\title{
Prerequisite factors for original equipment manufacturer remanufacturing
}

\author{
Johan Vogt Duberg, Gustav Johansson, Erik Sundin *, Jelena Kurilova-Palisaitiene \\ Division of Manufacturing Engineering, Department of Management and Engineering, Linköping University, 58183, Sweden
}

\section{A R T I C L E I N F O}

\section{Article history:}

Received 2 October 2019

Received in revised form 10 May 2020

Accepted 15 May 2020

Available online 17 June 2020

Handling editor: Yutao Wang

\section{Keywords:}

Remanufacturing

Remanufacturing transition

Production development

Production system

Circular economy

\begin{abstract}
A B S T R A C T
Natural resources are being depleted at an alarming rate, also resulting in increased emissions and pollution. The call for a circular economy and sustainable strategies is now louder than ever. Remanufacturing can alleviate our environmental impact while still providing opportunities for profitable business. However, there is a need for a framework detailing the necessary steps for a successful remanufacturing start-up. This paper aims to identify the essential and supportive factors an original equipment manufacturer (OEM) must consider when transitioning part of its business to remanufacturing. Such factors could aid both current actors in the industrial setting as well as make way for further investigations and more advanced frameworks from the scientific field. The task is carried out through a novel combination of prior research on production development and remanufacturing, with support from a case study performed at an electrical and electronic equipment (EEE) manufacturer. This paper concludes that the first essential factors to be addressed when switching orientation towards remanufacturing can be contained in four categories: core acquisition and reverse logistics, labor skill and availability, remanufacturing facilities, and remanufacturing process and technology. Secondary supporting factors include design for remanufacturing and information feedback, remanufacturing process improvements, remanufacturing market knowledge, and organization, planning and control.
\end{abstract}

( $) 2020$ The Authors. Published by Elsevier Ltd. This is an open access article under the CC BY-NC-ND license (http://creativecommons.org/licenses/by-nc-nd/4.0/).

\section{Introduction to remanufacturing and production development}

The difference between the emerging concept of the circular economy and the classic linear economy lies in the creation and handling of material waste. As the linear economy via production consumes resources to create waste and pollution, the circular economy has a limited impact on its environment, retaining the resources put into the system and creating comparatively small amounts of waste in its production processes (Murray et al., 2017). In a remanufacturing system, a used product is collected through a reverse channel, remanufactured and then sold (Östlin, 2008). Remanufacturing means that a used product, i.e., a core, is restored in an industrial process to a like-new condition (Lund, 1984), through a set of activities, e.g., inspection, cleaning, repair and testing (Sundin and Bras, 2005). The remanufacturing process could present both environmental and social benefits (Sundin et al., 2016), as well as economic benefits to its implementers (Demirel

\footnotetext{
* Corresponding author.

E-mail address: erik.sundin@liu.se (E. Sundin).
}

and Gökçen, 2008; Fleischmann et al., 2000).

One reason why remanufacturing is attractive from an environmental point of view is that the efforts made when manufacturing new parts, e.g., material extraction, material manufacturing, part manufacturing and product manufacturing, are fully or partly salvaged when performing remanufacturing. Remanufacturing contributes to great savings of energy and scarce raw material, and at the same time, solves the problem of valuable scrap waste (Sundin and Lee, 2011). Within the electrical and electronic equipment (EEE) sector, several environmental studies on the benefits of remanufacturing were published by, e.g., Kerr and Ryan (2001), Sundin and Tyskeng (2003), Lindahl et al. (2006), Gell (2008), Baustani et al. (2010), Goldey et al. (2010) and Kara (2010). These authors document how and why remanufacturing is preferable from an environmental perspective in comparison to new product manufacturing. How much better remanufacturing is varies depending on the products being studied, ranging from $14 \%$ to $60 \%$ regarding the environmental perspectives of increased resource efficiency and reduced emissions of $\mathrm{CO}_{2}$ equivalents.

Though economic factors followed by environmental and then social are, in order of significance, most commonly used for 
estimating the feasibility of remanufacturing (Goodall et al., 2014), the reasons for original equipment manufacturers (OEMs) to start remanufacturing processes differ between cases (Gallo et al., 2012). The greatest challenges to remanufacturing systems lie in the complexity, variability, and uncertainty of the intrinsic processes (Goodall et al., 2014; Lundmark et al., 2009; Sakao and Sundin, 2019; Seitz and Peattie, 2004).

Manufacturing strategy aims to give companies a competitive edge in the market through production (Hill, 1983; Skinner, 1969; Wheelwright, 1984). This connection is realized partly through the accurate selection and implementation of production systems (Miltenburg, 2005). Lekurwale et al. (2015) and Miltenburg (2008) divided manufacturing into six categories: human resources, process technologies, facilities, sourcing, organizational structure and control, and production planning and control. The category of human resources covers all aspects of the workforce, from wage rates and skill levels to required educational training and the ability to solve work-related challenges (Jayaram et al., 1999; Miltenburg, 2008) and how they affect the performance of the production system (Ahmad and Schroeder, 2003; Jayaram et al., 1999). In the process technology category, there are the functionality of the equipment, linkages of the production processes and the level of automation (Bellgran and Säfsten, 2009; Miltenburg, 2008). Facilities includes size, location (Miltenburg, 2008) and focus (Bellgran and Säfsten, 2009). Sourcing is the connection between the production system and other parts of the supply chain (Miltenburg, 2008), such as the delivery of materials or parts. Organizational structure and controls include decision-making procedures, culture, measurement tools, and relationships. Finally, production planning and production control includes knowledge and adaptation of the production flow and handling of new products (Bellgran and Säfsten, 2009; Miltenburg, 2008).

The term production development can be defined as the "development and operation of production systems" (Bellgran and Säfsten, 2009). In itself, the term encompasses the process planning and production assembly steps, following the product planning and design in the product realization process, which in turn is a part of the detailed product life cycle (Säfsten and Johansson, 2005). Hence, production development is a natural part of any manufacturing company's activities and one that is crucial for profitable and successful ventures. During the product introduction process, it is important to develop a plan for what a manufacturer wants to achieve with its product or product-service system. Should the objective be to provide a product with a neutral environmental footprint? Is it more important to deliver high quality at a premium price? Or is the focus on delivering cost-efficient products to the masses? For a traditional manufacturer, these are strategic decisions which affect its manufacturing capabilities (Hayes and Wheelwright, 1979; Lekurwale et al., 2015; Miltenburg, 2005), i.e., how well the company can coordinate its resources (Lekurwale et al., 2015; Miltenburg, 2005). For an OEM that pursues remanufacturing, a similar decision process must be conducted, but in this case, the product is already predetermined.

The objective of the authors of this paper is to identify the essential and supportive factors an OEM must consider when transitioning part of its business to remanufacturing.

The structure of this paper is as follows: In Section 2, the methodological approach of the paper is presented, followed by theoretical backgrounds on the subjects of interest in Section 3. Next, Section 4 describes the supporting case study. In Section 5, the acquired theories are combined and discussed to fulfill the objective of the paper, after which the results are summarized in Section 6. Finally, possible ideas for future research are discussed in Section 7.

\section{Research methodology}

To be able to distinguish between the two types of factors sought after in this paper, the terms essential factors and supportive factors needed to be defined. Essential factors were defined as factors absolutely necessary to enable a remanufacturing system. Supportive factors were defined as factors that could elevate the remanufacturing systems' capabilities and efficiency but still were not absolutely necessary for the functioning of the system.

A literature study was primarily used to achieve the purpose of this paper. The three main areas of research for the paper were investigated, creating a solid theoretical foundation. Literature was searched for in Google Scholar, Scopus, Business Source Premier and Emerald with the search words core acquisition, design, supply chain, facility, plant, location, sales, redistribution, reverse logistics and production system, in combination with remanufacturing. In addition to this, terms like product development, manufacturing strategy, manufacturing capability and decision factor were searched for using the same search engines. Further literature was found through the reference lists of previous literature and the reverse citing function provided by Google Scholar. Recommendations from experienced remanufacturing researcher peers also supported the literature study process.

This paper is based on research from a qualitative single case study on an EEE robotic lawn mower OEM called Husqvarna located in Sweden. Data about its current processes and potential locations for remanufacturing were acquired through semi-structured interviews. Recordings were made of all interviews, and the documented results were double-checked by the interviewees to ensure no misunderstandings were included in the dataset. These data were used to identify prerequisite factors for remanufacturing in a real-life setting. Table 1 describes the interviewees.

Concurrence between the case data and theory was utilized to develop interview questions with the goal of gaining awareness regarding parts of a remanufacturing decision factor.

\section{Prerequisite factors for OEM remanufacturing}

In this study, we have identified eight prerequisite factors for remanufacturing that are covered in the following subsections. The factors are core acquisition and reverse logistics, labor skill and availability, remanufacturing facilities, remanufacturing process and technology, design for remanufacturing and information feedback, remanufacturing process improvements, remanufacturing market knowledge, and organization, planning and control.

These factors expand upon the six manufacturing categories (see Section 1). The translation of these manufacturing categories into remanufacturing categories, or prerequisite factors, was

Table 1

Semi-structured interviews in the case study, arranged by interviewees' role in the supply chain.

\begin{tabular}{lc}
\hline Role of interviewee & Duration \\
\hline Logistics Director & $\sim 24 \mathrm{~min}$ \\
Research and Development Manager & $\sim 33 \mathrm{~min}$ \\
Regional Manager & $\sim 30 \mathrm{~min}$ \\
Lean Manager & $\sim 29 \mathrm{~min}$ \\
Supply Chain Manager & $\sim 21 \mathrm{~min}$ \\
After Sales Manager & $\sim 17 \mathrm{~min}$ \\
Project Manager & $\sim 34 \mathrm{~min}$ \\
Spare Parts Specialist & $\sim 34 \mathrm{~min}$ \\
Controller A & $\sim 18 \mathrm{~min}$ \\
Controller B & $\sim 21 \mathrm{~min}$ \\
Retailer A & $\sim 26 \mathrm{~min}$ \\
Retailer B & $\sim 28 \mathrm{~min}$ \\
\hline
\end{tabular}


conducted through the single case study where remanufacturing was planned for and implemented at an OEM and in the style of the remanufacturing system as presented by Östlin (2008). The remanufacturing system includes, e.g., core acquisition, reverse channels, customer relationships, and processing, which are interpreted into more general factors with a basis in the manufacturing categories. Instead of, e.g., the manufacturing category sourcing, we have core acquisition and reverse logistics. The other prerequisite factors follow the same analogy. The prerequisite factors were then defined through the literature study presented in the subsections of Section 3 and exemplified through the case study in Section 4.

\subsection{Core acquisition and reverse logistics}

One of the significant requirements for remanufacturing is the availability of cores (Sakao and Sundin, 2019), i.e., used products that can be restored to expected quality. In some circumstances, the cores are acquired naturally, e.g., through a product-service system (PSS) as part of a closed-loop supply chain (Fischer and Achterberg, 2016). In other circumstances, the cores are returned by the product owner either by choice or through the use of an incentive (Östlin et al., 2008b). Such returns may come from a multitude of different relations in the closed-loop supply chain, ranging from scrap yards and core brokers to the original end customers (Lind et al., 2014). Many companies have problems with acquiring cores for their processes (Sundin et al., 2016) and with the uncertainty of their quality (Kurilova-Palisaitiene et al., 2018; Ferrer, 2001).

Wei et al. (2015) showed that core acquisition management could be used to control the arrival rate and quality of collected cores. Part of core acquisition management includes the seven closed-loop supply chain relationships identified by Östlin et al. (2008b). One of them, voluntary-based, is without an incentive. The others are ownership-based, service-contract, direct-order, deposit-based, credit-based and buy-back. These latter relationships are different ways of providing value for the core owner, and their suitability depends on the product itself or upon the business model. As an example, credit-based returns can result in high administrative costs and uncertainty in the arrival of cores, while they help to ensure that the core owner buys another product from the same company as the credit is company-specific (Östlin et al., 2008b).

The findings of Wei et al. (2015) further expand into acquisition control, forecast return, quality classification, reverse channel and return strategies. These collectively manage how cores are collected, in what quality and quantity, and at what cost. These parts were confirmed to be important by Dunbäck and Sundin's (2011) multiple case study of reverse logistics challenges at six SMEs where controlling quantity, quality and timing of cores were identified as frequent challenges.

\subsection{Labor skill and availability}

As the variety in the processes of remanufacturing makes automation hard to implement, a remanufacturing process is normally highly labor-intensive (Guide and Van Wassenhove, 2001; Sakao and Sundin, 2019). The higher complexity and variation of the remanufacturing process furthermore sets requirements for highly skilled workers (Lund, 1984; Seitz and Peattie, 2004). The importance of access to labor is exemplified through some of the decision factors for facility location discussed in the next subsection.

\subsection{Remanufacturing facilities}

The selection of a remanufacturing facility location covers both the issues of a geographical location and partly the placement inside or outside the remanufacturer's current supply chain. When selecting a facility location, economic factors are not the only important ones to consider. Other aspects have also been shown to significantly impact the supply chain and its results (Cheng et al., 2015; Dowlatshahi, 2005). Logistics and labor factors, in combination with governmental and customer requirements, play important roles in the selection of a remanufacturing location (Lu et al., 2014). Such factors could be labor skill (Breitman and Lucas, 1987; Jakubicek and Woudsma, 2011; Karakaya and Canel, 1998) or proximity to transport infrastructure (Jakubicek and Woudsma, 2011; Karakaya and Canel, 1998; Min and Melachrinoudis, 1999). Ferrer and Whybark (2000) suggested location alternatives for remanufacturing as well as described their respective innate strengths and weaknesses. The experienced workforce in a previously established manufacturing plant, and the decreased number of transports when handling multiple facilities, exemplify labor, operational, and logistics prerequisites for a remanufacturing transition.

\subsection{Remanufacturing process and technology}

This subsection reviewed the process technology in terms of which production systems are suitable for remanufacturing, especially when planning for a new remanufacturing process. Similar analyses have been conducted by Kucner (2008), but in their research, the focus was on positioning remanufacturing in a product-process matrix and then tweaking the performance with a lean implementation approach. The authors of this article instead identified the main challenges of remanufacturing and then matched them with the manufacturing outputs that could overcome these challenges. For clarity, the authors re-emphasize that it is common for remanufacturing systems to have complex and uncertain processes (Goodall et al., 2014; Lundmark et al., 2009; Sakao and Sundin, 2019; Seitz and Peattie, 2004).

Flexibility is the only manufacturing output that helps to handle both the complexity and uncertainty of remanufacturing, as it sets up the production with the readiness to quickly adapt to changes. It was, therefore, identified as the main requirement for a production system suitable for remanufacturing to match the challenges stated by Lundmark et al. (2009), Sakao and Sundin (2019), and Seitz and Peattie (2004). Systems with low flexibility include continuous flow (Dallery and Stanley, 1992; Lee, 1992; Miltenburg, 2005) and equipment-paced line flow (Miltenburg, 2005). Lower production volumes (Seitz and Peattie, 2004) and the inability to fully automate a remanufacturing process due to variation (Sakao and Sundin, 2019) hinders these alternatives. Equipment-paced line flow could, however, be utilized in a remanufacturing process for standardized steps if its weaknesses are identified and considered. This is especially important to do, as many of the difficulties of remanufacturing are company-specific (Lundmark et al., 2009). Continuous flow, on the other hand, is fully specialized in short delivery times for products with little variation (Lee, 1992; Miltenburg, 2005), which makes it incapable of being adapted appropriately to a remanufacturing process.

Production systems based on the just-in-time (JIT) philosophy, in general, have high flexibility, but this can only be fulfilled if the material flow arrives just in time for the production (Miltenburg, 2005; Östlin and Ekholm, 2007), which could be interfered by the irregular core acquisition processes (Östlin and Ekholm, 2007). Problems could occur as the condition (Kurilova-Palisaitiene et al., 2018), amount (Lundmark et al., 2009; Wei et al., 2015) and arrival distribution of cores (Wei et al., 2015) usually are uncertain. Furthermore, issues with core acquisition are often highlighted as problem areas (Sundin et al., 2016), making JIT not suitable for 
remanufacturing. However, some principles from JIT could be utilized for other production systems to enhance their manufacturing outputs by eliminating wastes, as described by Fullerton and McWatter (2001).

The characteristics of the product, as well as the planned volume, determine which production system is suitable. An extension of Miltenburg (2005) framework, with suitability for remanufacturing as additional information, is provided in Table 2.

\subsection{Design for remanufacturing and information feedback}

Products designed for remanufacturing lower the processes' complexity and the qualification standards for the labor force (Lundmark et al., 2009), encourage future remanufacturing possibilities (Östlin et al., 2009), and amplify the potential environmentally beneficial effects of remanufacturing (Kerr and Ryan, 2001) as well as the economic (Sundin, 2004). However, it is not common to include design for remanufacturing approaches during the initial design phases (Kurilova-Palisaitiene et al., 2018), and when OEMs decide to transition towards remanufacturing, it is often too late to make major design changes (Subramoniam et al., 2013). Furthermore, most of the design for remanufacturing tools and concepts developed by academia are not used in industry because the tools are often complex, difficult to use or require a significant amount of data which is unavailable in initial phases of design for remanufacturing (Hatcher et al., 2011). However, introducing often-lacking information channels from remanufacturing to traditional departments could increase the awareness for remanufacturing and highlight the design-related problems in remanufacturing. This awareness could then in its turn support product design for remanufacturing (Lindkvist Haziri et al., 2019). Further explorations of how to implement such information feedback from remanufacturing departments to design departments is described by Lindkvist and Sundin (2019).

\subsection{Remanufacturing process improvements}

According to Guide (2000), there is an industry need for planning and control techniques adapted for remanufacturing. Some of the current remanufacturers use material requirement planning (MRP) systems with principles of, e.g., JIT, kanban and theory of constraints (TOC) in their planning, but remanufacturers must be able to handle other activities and obstacles than traditional manufacturers.

The uncertainties of core acquisition and the labor-intensive process of remanufacturing make automation and mass production hard to implement (Sakao and Sundin, 2019). Due to these reasons, lean principles practiced at manufacturing are hard to implement as well (Seitz and Peattie, 2004). In industries like the automotive industry, the uncertainty regarding core arrival and core quality poses too large a problem for any holistic lean implementation (Pawlik et al., 2013). There is, however, research on the practical application and benefits of lean in remanufacturing settings (Kurilova-Palisaitiene et al., 2018; Sundin, 2006; Östlin and Ekholm, 2007). The field is in great expansion, and appropriate implementations can offer strong competitive advantages (Durakovic et al., 2018).

\subsection{Remanufacturing market knowledge}

Product-service systems, a combination of products and services that together satisfy the needs of the client (Tukker and Tischner, 2006), have been shown to empower companies in the transition to a circular economy (Fischer and Achterberg, 2016; Yang et al., 2018). Functional sales further give a company increased control over the flow of cores (Fischer and Achterberg, 2016; Sundin and Bras, 2005; Kurilova-Palisaitiene et al., 2018).

As demand rates tend to be lower for remanufactured products than for manufacturing, it can also be more challenging to achieve economies of scale within remanufacturing (Seitz and Peattie, 2004). This could become an issue as remanufactured products usually are sold for less than their original counterparts (Thierry et al., 1995; Seitz and Peattie, 2004; Östlin et al., 2008b); however, a reduced price is needed to enhance customer interest in the remanufactured products (Abbey et al., 2019; Wei et al., 2015) and should not affect the profitability of remanufacturing due to the material and energy savings achieved by remanufacturing (Östlin et al., 2008a). The lower costs of remanufactured products also allow for premium brands to compete with low-cost producers, broadening their reach and competitiveness on the market (Atasu et al., 2008). This increase in scope, together with the consumer shifts from economic and social considerations towards environmental considerations (Dobson, 2007), makes the remanufactured product more readily available for the masses. However, consumers may consider remanufactured products to be of inferior quality to the original, even though that is often not the case (Parker et al., 2015). The willingness to purchase a specific remanufactured product is useful to investigate before the remanufacturing initiation due to pricing issues and, if feasible, to resolve any possible negative perception of the remanufactured product in question.

\subsection{Organization, planning and control}

This factor entails decision-making procedures, measurement tools, and planning of the remanufacturing process. Approaches and arrangement of pre-studies is one aspect of this factor, as is documentation and performance measurement of the started processes.

During the product introduction process, the preparatory activities for initiating production of the product are performed (Johansen, 2005). These activities include those required to make the product remanufacturable and to prepare for the efficient integration of the product and its production system (Bellgran and Säfsten, 2009; Juerging and Milling, 2005).

Similarly, different types of pre-series (or pilot) production and ramp-up can be collectively described as production start-up (Clark

Table 2

Suitability of production systems for remanufacturing (adapted from Johansson and Vogt Duberg (2019)).

\begin{tabular}{lll}
\hline & Suitability for remanufacturing & Volume (Miltenburg, 2005) \\
\hline Job shop & Yes & Very low \\
Batch flow & Yes & Low \\
Operator-paced line flow & Yes & Medium \\
Flexible manufacturing system & Yes & Medium \\
JIT & No, high uncertainty will cause issues & Low to medium \\
Equipment-paced line flow & Yes & High \\
Continuous flow & No, low capability for variety & Very high \\
\hline
\end{tabular}


and Fujimoto, 1991), a term that slightly overlaps the product introduction process as it also may include preceding prototype steps (Bellgran and Säfsten, 2009). Final verification is a term that is interchangeable with production start-up, only that it excludes prototype steps, but similarly aims to prepare the product and production system for the start of production (Almgren, 1999). In low-volume manufacturing industries, the contents of the product introduction process may exclude production start-up due to the high costs associated with extra production runs, the low production volumes in general, and the volatile demand of those products (Javadi et al., 2016).

As an already existing product that, at its height, is modified to achieve a like-new status, the newness in product terms does not add the major part of complexity to the production introduction process. The production system can be hard to utilize, as the difference in quantities produced and to be remanufactured can be large, calling for different types of production systems and equipment. Due to the higher complexity caused by the need for a modified production system, it is important that the selected production system is suitable for remanufacturing of the product, to ensure an effective process. However, if the remanufacturing occurs in a low-volume manufacturing industry, the differences are further diminished, thereby reducing the resulting complexity (Javadi et al., 2016). This suggests that a company starting remanufacturing should do so on a smaller scale, as it would enable them to gain experience on the required processes while still assuring high quality remanufacturing.

\section{Case description of OEM robotic lawn mower remanufacturing initiation}

Through the 14 interviews, information about the current supply chain of a premium EEE robotic lawn mower OEM was collected. The goal of the interviews was to identify the prerequisite factors for the remanufacturing of the OEM's products and to find connections to the factors described in Section 3. Initially, the case study OEM needed support in deciding where in the supply chain the remanufacturing process could be located. Five potential scenarios for remanufacturing were found, and their prospects for housing a new remanufacturing process were explored through the semi-structured interviews. The five scenarios were current international manufacturing plants, current spare parts warehouses, new locations, third-party remanufacturing, and decentralized remanufacturing at the retailers. These scenarios are more thoroughly described in the study by Vogt Duberg et al. (2020).

\subsection{Remanufacturing prerequisite factors - a case of robotic lawn mowers}

In the upcoming subsections, the case study data is presented regarding the eight identified prerequisite factors of remanufacturing.

\subsubsection{Core acquisition and reverse logistics}

The retailers of the OEM currently handle all service activities for the robotic lawn mowers in circulation. In most cases, the customers return the product to the retailers when service is needed and if the product is of manageable dimensions and weight. In other cases, the customers utilize a service collecting offering where the retailer collects the lawn mower directly from the customer.

For a remanufacturing process, a similar procedure was planned to be utilized. Some retailers had previous experience of retrieving old products from their customers, usually when they decided to purchase a new model. Therefore, no major adjustments to the existing logistics network were identified as necessary. In some cases, the new purchase was discounted based on the age and condition of the returned product. As old products already have been processed at some retailers, there was confidence in that it was possible to acquire cores for remanufacturing. Furthermore, a monetary incentive is planned to be used to acquire suitable cores for remanufacturing.

As the retailers are of varying sizes, having different capacity constraints and capabilities, all of them would not be able to manage a remanufacturing process. However, some retailers were willing to transfer cores to other retailers. This requires an addition to the existing logistics network, but only a minor change in terms of scheduling more transports as the current infrastructure and logistics network could be utilized. This also applies to the acquisition of cores, where a reverse flow was needed similar to the existing service collection system.

\subsubsection{Labor skill and availability}

The OEM's already extensive retail network possesses the required competence for a remanufacturing process from its previous experience of repairing and servicing the product, making it suitable for managing a remanufacturing process. However, this applies only to the most experienced retailers. Therefore, for the start-up phase of remanufacturing, suitable retailers had to be identified and properly trained.

The remanufacturing processes mainly required manual labor, thus incurring high labor costs. However, as the workload on the retailers in this industry is seasonally dependent, existent personnel were often available for additional tasks. In these cases, the remanufacturing processes are expected to be performed without any direct additional labor costs as the personnel otherwise would have been idle.

\subsubsection{Remanufacturing facilities}

Based on the interview results (Table 3) and an economic evaluation of the scenarios by Vogt Duberg et al. (2020), a transition towards remanufacturing with a decentralized approach, incorporating the retailers, was identified as the most feasible scenario. The main advantages were that it required no significant investments and could utilize existing expertise and the retailers' close proximity to customers. Therefore, the current facilities and infrastructure could be used for both the supply of materials and to facilitate the remanufacturing processes.

\subsubsection{Remanufacturing process and technology}

As the retailers have a relatively low capacity, at least in their current state, a high volume from each of them is not expected. However, the retail network would have the capacity, as a combined force, to reach high volumes while also reaching a broad range of customers. The retailers have existing workshops for service purposes, which are planned to be utilized for remanufacturing. It was, therefore, proposed to focus on either a job shop or batch flow as suitable production systems in accordance with Table 2.

Replacement parts are central in the remanufacturing process of this product. Some of the components were planned to be replaced, while others could be cleaned and polished to obtain the desired condition. In the initial phase, any restoration of the replaced components was not considered, as this would have added complexity to the initial process. However, this is suggested to the OEM to investigate at a later stage in an attempt to increase profitability and reduce material and energy consumption.

The product is built with service in mind, making it somewhat easy to open and replace components without specialized tools. Hence, no investment in expensive equipment would be needed to start remanufacturing. For future efficiency programs, equipment 
Table 3

Respondent perceptions of important prerequisite factors for remanufacturing.

\begin{tabular}{|c|c|}
\hline Number of occurrences & Factors \\
\hline 5 & Transport costs for all parts of the remanufacturing system \\
\hline \multirow[t]{2}{*}{4} & Competence is available at possible remanufacturing site \\
\hline & Feasibility to convert part of current processes and space is available for that at the possible remanufacturing site \\
\hline \multirow[t]{3}{*}{3} & Spare part availability \\
\hline & Minimal interference with current production activities \\
\hline & Need or no need for full-time workers \\
\hline \multirow[t]{4}{*}{2} & Proximity to customer \\
\hline & Possibility of gaining economies of scale \\
\hline & Availability of skills training \\
\hline & No need to build additional infrastructure \\
\hline \multirow[t]{3}{*}{1} & Possibility of standardization \\
\hline & No need for additional equipment \\
\hline & Avoidance of regulation problems with product transportation \\
\hline
\end{tabular}

for things like quicker cleaning, disassembly and assembly could be developed.

\subsubsection{Design for remanufacturing and information feedback}

For the initial phase of remanufacturing, it is not planned to utilize a product that is already designed for remanufacturing. There are, however, design improvements that can be made to upcoming product models, as shown by the product design analysis by Bergstrand and Broman (2019). Design improvements they suggested included reducing the risk of incorrect assembly by making components only fit one way (i.e., poka-yoke), minimizing the need for changing tools, and reducing the number of movements or rotations needed when disassembling the product. The goal of the improvements was to make the remanufacturing process both easier and quicker with reduced chances of mistakes.

For changes to the design, an information flow is needed directly from the retailers to the product development department. Such steps toward a feedback loop of information have yet to be investigated.

\subsubsection{Remanufacturing process improvements}

Along with the identified replacement components, a set of remanufacturing guidelines were also proposed to the OEM to achieve standardization in the process, and consistent quality of the finished product at each of the decentralized sites.

Further improvements in terms of choosing planning methods, lean principles or other production philosophies have not been considered in the current state.

\subsubsection{Remanufacturing market}

For the initial process of deciding which model or models of the OEM's products were the most promising in a remanufacturing context, historical sales data was investigated. Which models had high sales volumes as well as an innate value worthwhile attempting to recover? The thought process behind a high volume was that it should be easy to collect cores while also having a potential market for remanufactured products as they are similar to new products. The value was important in trying to ensure that the remanufacturing process had any potential of being profitable.

Kabel et al. (2020) investigated the consumer purchase intention of the robotic lawn mower product and showed that the customers are positive to a remanufactured product if it holds the same quality attributes as what the OEM delivers in its new products. This increased the confidence that an appropriate product had been chosen for remanufacturing, as the OEM would focus on delivering a high-quality product.

Incorporating remanufacturing into the OEM's business model was briefly reviewed. Areas of current interest include sales policies and warranty programs. As an OEM with a focus on delivering premium products, it was essential to provide the customers with confidence that the remanufactured product met the same quality standards as a new product in terms of durability and functionality.

\subsubsection{Organization, planning and control}

The approach for the OEM's new remanufacturing process followed a hierarchical structure, where information was collected and presented by workers lower in the chain of command. Outlining the next steps in the project and introducing adjustments required approval from higher management.

The currently planned decentralized process would utilize lowvolume production systems like job shop or batch flow, as stated in Subsection 4.1.4. A new process for remanufacturing, like the current production process of the manufacturing plants, would utilize the production system operator-paced line flow. However, the current service processes at the retailers' level are commonly structured as a job shop or batch flow. If these production systems are kept, there will be less new complexity that the retailers must handle, making their transition to facilitate remanufacturing easier.

Any performance measurements of the proposed remanufacturing system have yet to be discussed in detail or to be put in place, but can be further researched at a later stage.

\subsection{Respondent perceptions and questions for remanufacturing prerequisites}

During the interviews, questions were posed regarding the importance of different factors in a remanufacturing scenario related to the respondents' expertise and professional judgement. The respondents ranged from higher management to retail. The identified factors for remanufacturing decision making brought up by the respondents during these interviews can be found in Table 3. These factors covered skill level requirements, transports and availability of materials, labor costs, production processes and equipment, and customer behavior.

The factors included in Table 3 correspond to the theory discussed in the subsections of Section 3. Labor skill, infrastructure proximity (interpreted as transport costs), and utilization of existing facilities exemplify the needed connections and are part of the six manufacturing categories, which, together with manufacturing outputs, build upon the existing manufacturing capabilities.

The types of location alternatives for remanufacturing found in the case also closely resemble the suggestions of Ferrer and Whybark (2000), further reinforcing the ties between the actual case and theoretical factors. Due to these ties, it was deemed relevant to encompass all the interview responses into the question set, provided they bore relevance to at least one investigated factor 
type, namely labor (connected to issues raised in Subsections 4.1.2 and 4.1.3), operational (connected to issues raised in Subsections 4.1.3 and 4.1.4), or logistics (connected to issues raised in Subsections 4.1.1 and 4.1.3).

In Table 4, the resulting questions and their factor type are listed. These questions can be used by other OEMs with similar products that require an investigation of their possibilities of transitioning to remanufacturing.

\section{Discussion and results of factor importance}

Based on the amassed theory and case study results, the individual importance of the eight prerequisite factors will be discussed in this section.

Remanufacturing and manufacturing have many similarities since both are industrial processes with inputs and outputs. However, remanufacturing rebuilds a product instead of building it from scratch, resulting in other challenges that must be conquered. One of the most elemental prerequisites of remanufacturing is the availability of cores; without cores, there is no remanufacturing. With this argument, core acquisition and reverse logistics is an essential factor to consider when implementing a remanufacturing process. Traditional manufacturing based on a linear model does not have a reverse logistics channel, but remanufacturing as part of a circular economy does, the reason being the flow of cores, which are delivered to the remanufacturing process from the user.

The lean philosophy for remanufacturing is built upon the Japanese success, and then further expanded upon by trying to conquer the challenges of remanufacturing, i.e., complexity and uncertainty. This has been shown by Kurilova-Palisaitiene et al (2018) and Seitz and Peattie (2004), among others. Östlin and Ekholm (2007) found that lean principles are especially difficult to implement to their fullest potential due to the lack of JIT for deliveries, while other parts, such as layout and equipment positioning, are easier to implement. This shows that efficiency programs for manufacturing can be and are implemented for remanufacturing. However, the principles must be adapted accordingly. By implementing elements of the remanufacturing process improvements factor, it is possible to achieve a more efficient process and reach higher capabilities. A process will, however, work without the improvements, thus making this a supporting factor. This is further motivated by the case study, where the OEM in the planning state did not consider potential efficiency programs.

Lindkvist Haziri and Sundin (2019) highlightthe importance of feedback to overcome a set of barriers, which hinders the product design process. Without this, it is difficult to benefit from the positive effects of design for remanufacturing shown by, e.g., Lundmark et al. (2009), Kerr and Ryan (2001) and Sundin (2004). These positive effects benefit a remanufacturing process, but they are not fundamentally required for it, and neither for the case study OEM. The positive effects motivate the classification of design for remanufacturing and information feedback to be a supporting factor for remanufacturing.

Remanufacturing market knowledge is an important factor for the case study OEM as it requires a sellable product. However, remanufacturing can still be performed without any market knowledge by hoping for success, though it is a risky approach. Market knowledge is vital from a business perspective, but not essential for remanufacturing in itself. It is a supporting factor, which lowers risks and enhances the possibilities of achieving market success.

Remanufacturing is often labor-intensive (Guide and Van Wassenhove, 2001; Sakao and Sundin, 2019), thus making the availability of labor a requirement of the process. To achieve high flexibility outputs, it is also important to have a labor force with high skill levels to deliver high manufacturing capabilities. The complex and uncertain nature of remanufacturing sets high skill levels as requirements on the remanufacturing workers (Lund, 1984; Seitz and Peattie, 2004). The production systems with high flexibility had the best capabilities for handling remanufacturing, which were the low-volume labor-intensive systems, e.g., job shop and batch flow. This was also made clear in the case study, where only the most experienced retailers would get the opportunity to remanufacture the OEM's products, which is connected to both the retailers' labor skill and availability. The OEM would have difficulties to handle the process by itself as it has neither experience in working with the product nor available workers. The production systems based on automation (e.g., equipment-paced line flow, flexible manufacturing system) are neither labor intensive nor sufficiently flexible (Miltenburg, 2005). Therefore, these systems do not need labor to the same degree, but nonetheless, the uncertain, variable and complex remanufacturing processes require labor to some extent. This makes the labor skill and availability an essential factor.

Remanufacturing facilities is also an essential factor. The reason for this is that remanufacturing is an industrial process and would, therefore, require a facility for the remanufacturing process, inventory of materials and finished products as well as for housing the required equipment and cores. The location of the remanufacturing facility is also vital, as it could ease both logistics and labor factors, as stated by Lu et al. (2014). No proximity of infrastructure or other essential factors would limit the possibilities of remanufacturing. One of the reasons the case study OEM did not want to

Table 4

A set of questions for an OEM to identify its prerequisite factors for remanufacturing.

\begin{tabular}{ll}
\hline Type of factor & Questions \\
\hline Labor & What is the skill level at or nearby the site? \\
& How can competence be acquired? \\
Operations & Are dedicated remanufacturing workers required? \\
& Can the facilities be adapted for remanufacturing? \\
& Is large-scale, low-cost production possible? \\
& Are standardized processes and consistent quality possible? \\
& Would a remanufacturing process interfere with existing activities? \\
Logistics & Which equipment or machines are required? \\
& Is it required to invest in new infrastructure? \\
& Can the existing logistics network be utilized? \\
& What is the transport cost to and from the market? \\
& Does the location result in additional complexity in terms of jurisdictions? \\
& How are spare parts provided? \\
& Can cores be acquired directly from the end-customer? \\
\hline
\end{tabular}


form a small-scale remanufacturing system run by themselves was that it would have required high initial costs to build a facility for remanufacturing, including investing in the required equipment. It was easier to involve its retailers instead, who already had facilities suitable for the remanufacturing processes.

The core of remanufacturing is the process that transforms the core into a remanufactured product. Like the core acquisition and reverse logistics factor, it is not possible to remanufacture without a core; neither is it possible to deliver a remanufactured product without a working process and technology that allows cores to be restored to "like-new" condition. The remanufacturing process and technology factor is, therefore, essential. These elements include the choice of production system, which sets the basis for delivering the products in a certain quantity with the expected attributes. It is vital not to select a system that is incapable of managing the uncertainty and complexity of remanufacturing. This is another reason for its essential status.

Much like how marketing knowledge greatly impacts the resulting economic benefits of remanufacturing implementation, the organization, planning and control factor impacts the efficiency of the implementation and ongoing process as a whole. Without clear decision processes and performance measures, it is unclear who is responsible for each part of the remanufacturing system and if the system is working as intended. However, a lack of this factor does not spell the end for any remanufacturing implementation, making this a supporting factor. If there are individuals committed to realizing a remanufacturing project, it is certainly possible for them to influence the surrounding links in the supply chain and to start-up a remanufacturing process. However, the lack of control and planning will make it difficult to sustain the activities and to learn lessons for the future from them.

These factors are summarized in Fig. 1, where the internal parts of the "remanufacturing rocket" represent the four essential factors. The wings, containing the supporting factors, enhance the remanufacturing rocket by improving the chances of reaching the desired destination.

\subsection{Essential remanufacturing factors}

The essential factors an OEM must consider when transitioning part of its business towards remanufacturing were found to be four of the integral decision-making factors of manufacturing with additions of unique remanufacturing issues:

- Core acquisition and reverse logistics (sourcing). Questions connected to logistics factors for remanufacturing are presented in Table 4.

- Labor skill and availability (human resources). Skilled and competent workers necessary for the remanufacturing processes. Questions connected to labor factors for remanufacturing are presented in Table 4.

- Remanufacturing facilities (facilities). Proximity to other supply chain links and the market, impact of other location factors depending on the remanufacturer, centralized or decentralized remanufacturing. Questions connected to facility location factors for remanufacturing are presented in multiple categories in Table 4.

- Remanufacturing process and technology (process technology). Equipment needed and suitable production system for the remanufacturing processes. For the suitability of production systems regarding remanufacturing, see Table 2. Questions connected to operational factors for remanufacturing are presented in Table 4.

\subsection{Supporting remanufacturing factors}

In addition to the essential factors presented in the previous subsection, there are still several important factors and tools that can elevate the remanufacturing capabilities and results of an OEM:

- Design for remanufacturing and information feedback, as discussed in Subsection 3.5.

- Remanufacturing process improvements, for example, lean implementations, as mentioned in Subsection 3.6.

- Remanufacturing market knowledge, for implementation of supportive business models, for example, leasing or PSS, as detailed in Subsection 3.7.

- Organization, planning, and control to ensure a smooth implementation and enhanced functioning of future activities.

\section{Conclusions}

This paper presents eight prerequisite factors to remanufacturing that are identified through a literature study and exemplified and applied through a single case study of a premium EEE robotic lawn mower OEM. These factors state what is necessary to consider when planning for transitioning part of the manufacturing to remanufacturing. The factors are also further divided into two sets, the essential and supporting remanufacturing factors. These are illustrated in the "remanufacturing rocket" (Fig. 1), where the essential factors construct the main body of the rocket. Without the main body, there is no rocket, and thus no remanufacturing will happen. But once these four essential factors are combined - core acquisition and reverse logistics, labor skill and availability, remanufacturing facilities, and remanufacturing process and technology - the remanufacturing process can be launched.

However, without the supporting factors - design for remanufacturing and information feedback, remanufacturing process improvements, remanufacturing market knowledge, and organization, planning, and control - it can be hard to manage remanufacturing, and its successfulness is likely limited. The supporting factors are illustrated as wings in the "remanufacturing rocket" as the rocket can be flown without these, but once the wings are installed, the rocket is much easier to control and fly to its desired destination.

A small set of interview questions are also presented in this paper that could be applied to other companies that wish to collect information about prerequisites for their businesses in the fields of operations, labor and logistics connected to remanufacturing.

\section{Future research}

The presented prerequisite factors in this paper can be further expanded upon to include other aspects that were not found during this study. Further case studies are also needed to validate the prerequisites and their categorization into essential and supporting factors. More applied research and case studies can improve the generalizability of the results to be applicable to more companies than large OEMs with retailer network setups.

\section{CRediT authorship contribution statement}

Johan Vogt Duberg: Data curation, Formal analysis, Investigation, Methodology, Resources, Software, Validation, Visualization, Writing - original draft, Writing - review \& editing. Gustav Johansson: Conceptualization, Data curation, Formal analysis, Investigation, Methodology, Resources, Software, Validation, Visualization, Writing - original draft, Writing - review \& editing. Erik Sundin: Funding acquisition, Project administration, Resources, Supervision, Visualization, Writing - original draft, Writing - review 


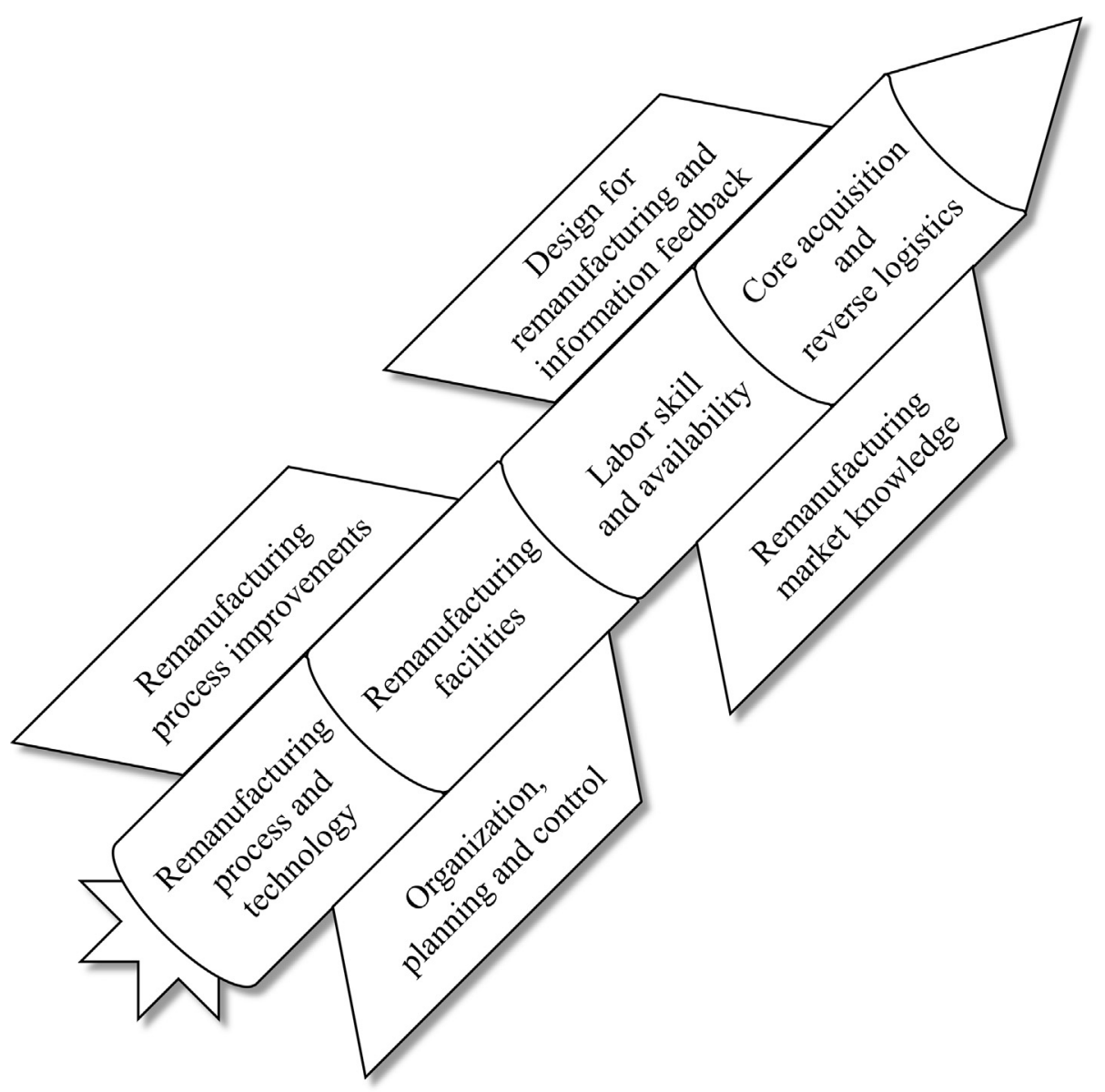

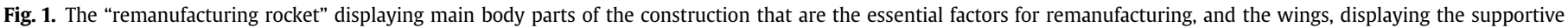
factors, for launching a successful remanufacturing journey.

\& editing. Jelena Kurilova-Palisaitiene: Funding acquisition, Methodology, Project administration, Supervision, Writing - original draft, Writing - review \& editing.

\section{Declaration of competing interest}

The authors declare that they have no known competing financial interests or personal relationships that could have appeared to influence the work reported in this paper.

\section{Acknowledgements}

The authors would like to thank the case company, Husqvarna $A B$, for supporting this research. We are also thankful for the financial support provided by the VINNOVA Challenge-driven innovation initiative and the project ElevatoRe: Elevate remanufacturing to EEE manufacturers' strategy towards circular economy (Dnr: 2018-00330).

\section{References}

Abbey, J.D., Kleber, R., Souza, G.C., Voigt, G., 2019. Remanufacturing and consumers' risky choices: behavioral modeling and the role of ambiguity aversion. J. Oper. Manag. 65 (1), 4-21. https://doi.org/10.1002/joom.1001.

Ahmad, S., Schroeder, R.G., 2003. The impact of human resource management practices on operational performance: recognizing country and industry differences. J. Oper. Manag. 21, 19-43. https://doi.org/10.1016/S0272-6963(02) 00056-6.

Almgren, H., 1999. Pilot Production and Manufacturing Start-Up in the Automotive Industry. Principles for Improved Performance. Chalmers University of
Technology, Gothenburg.

Atasu, A., Guide, V.D.R., Van Wassenhove, L.N., 2008. Product reuse economics in closed-loop supply chain research. Prod. Oper. Manag. 17 (5), 483-496. https:// doi.org/10.3401/poms.1080.0051.

Baustani, A., Sahni, S., Graves, S.C., Gutowski, T.G., 2010. Appliances remanufacturing and life cycle energy and economic savings. In: Proceedings of the 2010 IEEE International Symposium on Sustainable Systems and Technology. https:/| doi.org/10.1109/ISSST.2010.5507713.

Bellgran, M., Säfsten, E.K., 2009. Production Development: Design and Operation of Production Systems. Springer Science \& Business Media. https://doi.org/ 10.1007/978-1-84882-495-9.

Bergstrand, O., Broman, T., 2019. Analysis of the Design of a Robotic Lawnmower from a Remanufacturing Perspective, Linköping: Bachelor's Thesis. Linköping University.

Breitman, R.L., Lucas, J.M., 1987. PLANETS: a modeling system for business planning. Interfaces 17 (1), 94-106. https://doi.org/10.1287/inte.17.1.94.

Cheng, Y., Farooq, S., Johansen, J., 2015. International manufacturing network: past, present, and future. Int. J. Oper. Prod. Manag. 35 (3), 392-429. https://doi.org/ 10.1108/IJOPM-03-2013-0146.

Clark, K.B., Fujimoto, T., 1991. Product Development Performance: Strategy, Organization, and Management in the World Auto Industry. Harvard Business School Press, Boston, Massachusetts.

Dallery, Y., Stanley, B.G., 1992. Manufacturing flow line systems: a review of models and analytical results. Queue. Sys. Theory Appl. Special Issue Queue Model Manuf. Sys. 12, 3-94. https://doi.org/10.1007/BF01158636.

Demirel, N.Ö., Gökçen, H., 2008. A mixed integer programming model for remanufacturing in reverse logistics environment. Int. J. Adv. Manuf. Technol. 39, 1197-1206. https://doi.org/10.1007/s00170-007-1290-7.

Dobson, A., 2007. Environmental citizenship: towards sustainable development Sustain. Dev. 15 (5), 276-285. https://doi.org/10.1002/sd.344.

Dowlatshahi, S., 2005. A strategic framework for the design and implementation of remanufacturing operations in reverse logistics. Int. J. Prod. Res. 43 (16), 3455-3480. https://doi.org/10.1080/00207540500118118.

Dunbäck, O., Sundin, E., 2011. Reverse logistic challenges within the remanufacturing of automotive components. Glasgow, UK. In: Proceedings of 1st International Conference on Remanufacturing, pp. 74-82. July 26-29. 
Durakovic, B., Demir, R., Abat, K., Emek, C., 2018. Lean manufacturing: trends and implementation issues. Period. Eng. Nat. Sci. 6 (1), 130-143. https://doi.org/ 10.21533/pen.v6i1.45.

Ferrer, G., 2001. On the widget remanufacturing operation. Eur. J. Oper. Res. 135 (2), 373-393. https://doi.org/10.1016/S0377-2217(00)00318-0.

Ferrer, G., Whybark, D.C., 2000. From garbage to goods: successful remanufacturing systems and skills. Bus. Horiz. 43 (6), 55-64. https://doi.org/10.1016/S00076813(00)80023-3.

Fischer, A., Achterberg, E., 2016. Create a Financeable Circular Business in 10 Steps, Circle Economy, Sustainable Finance Lab, Amsterdam.

Fleischmann, M., Krikke, R.H., Dekker, R., Flapper, S.D.P., 2000. A characterisation of logistics networks for product recovery. Omega 28 (6), 653-666. https:// doi.org/10.1016/S0305-0483(00)00022-0.

Fullerton, R.R., McWatters, C.S., 2001. The production performance benefits from JIT implementation. J. Oper. Manag. 19, 81-96. https://doi.org/10.1016/S02726963(00)00051-6.

Gallo, M., Romano, E., Santillo, L.C., 2012. A perspective on remanufacturing business: issues and opportunities. In: Bobek, V. (Ed.), International Trade from Economic and Policy Perspective. InTechOpen, pp. 209-234. https://doi.org/ $10.5772 / 48103$.

Gell, M., 2008. Carbon Footprints and Ecodesign of Toner Cartridges. Xanfeon Energy \& Environmental Services, UK.

Goldey, C.L., Kuester, E.-U., Mummert, R., Okrasinski, T.A., Olson, D., Schaeffer, W.J., 2010. Lifecycle assessment of the environmental benefits of remanufactured telecommunications product within a "green" supply chain. Arlington, USA. In: Sustainable Systems and Technology (ISSST), 2010 IEEE International Symposiu. m, pp. 1-6. https://doi.org/10.1109/ISSST.2010.5507761.

Goodall, P., Rosamond, E., Harding, J., 2014. A review of the state of the art in tools and techniques used to evaluate remanufacturing feasibility. J. Clear Prod. 81, 1-15. https://doi.org/10.1016/j.jclepro.2014.06.014.

Guide, V.D.R., 2000. Production planning and control for remanufacturing: industry practice and research needs. J. Oper. Manag. 18 (4), 467-483. https://doi.org/ 10.1016/S0272-6963(00)00034-6.

Guide, V.D.R., Van Wassenhove, L.N., 2001. Managing product returns for remanufacturing. Prod. Oper. Manag. 10 (2), 142-155. https://doi.org/10.1111/j.19375956.2001.tb00075.x.

Hatcher, G., Ijomah, W., Windmill, J., 2011. Design for remanufacture: a literature review and future research needs. J. Clean. Prod. 19 (17-18), 2004-2014. https://doi.org/10.1016/j.jclepro.2011.06.019.

Hayes, R.H., Wheelwright, S.C., 1979. Link manufacturing process and product life cycle. Harv. Bus. Rev. 57 (1), 133-140.

Hill, T.J., 1983. Manufacturing's strategic role. J. Oper. Res. Soc. 34 (9), 853-860. https://doi.org/10.1057/jors.1983.182.

Jakubicek, P., Woudsma, C., 2011. Proximity, land, labor and planning? Logistics industry perspectives on facility location. Transport. Lett. Int. J. Transport Res. 3 (3), 161-173. https://doi.org/10.3328/TL.2011.03.03.161-173.

Javadi, S., Bruch, J., Bellgran, M., 2016. Characteristics of product introduction process in low-volume manufacturing industries: a case study. J. Manuf. Technol. Manag. 27 (4), 535-559. https://doi.org/10.1108/jmtm-03-2015-0017.

Jayaram, J., Droge, C., Vickery, S.K., 1999. The impact of human resource management practices on manufacturing performance. J. Oper. Manag. 18 (1), 1-20. https://doi.org/10.1016/S0272-6963(99)00013-3.

Johansen, K., 2005. Collaborative Product Introduction within Extended Enterprises. Linköping: Doctoral dissertation. Department of Mechanical Engineering, Linköping University.

Johansson, G., Vogt Duberg, J., 2019. Economic Potential for Remanufacturing of Robotic Lawn Mowers with an Existent Forward Supply Chain,. Linköping: Master's thesis. Linköping University.

Juerging, J., Milling, P.M., 2005. Interdependencies of product development decisions and the production ramp-up. Boston, MA, USA. In: The 23rd International Conference of the System Dynamics Society.

Kabel, D., Elg, M., Sundin, E., 2020. Consumer purchase intention of remanufactured EEE products. Grenoble, France 27th CIRP Life Cycle Eng (LCE) (Accepted).

Kara, H., 2010. Comparative Carbon Footprint Analysis of New and Remanufactured Inkjet Cartridges. Center for Remanufacturing and Reuse.

Karakaya, F., Canel, C., 1998. Underlying dimensions of business location decisions. Ind. Manag. Data Syst. 98 (7), 321-329. https://doi.org/10.1108/ 02635579810205395.

Kerr, W., Ryan, C., 2001. Eco-efficiency gains from remanufacturing: a case study of photocopier remanufacturing at Fuji Xerox Australia. J. Clean. Prod. 9 (1), 75-81. https://doi.org/10.1016/S0959-6526(00)00032-9.

Kucner, R.J., 2008. A Socio-Technical Study of Lean Manufacturing Deplayment in the Remanufacturing context. Dissertation. The University of Michigan.

Kurilova-Palisaitiene, J., Sundin, E., Poksinska, B., 2018. Remanufacturing challenges and possible lean improvements. J. Clean. Prod. 172, 3225-3236. https:/ doi.org/10.1016/j.jclepro.2017.11.023.

Lee, Q., 1992. Manufacturing focus - a comprehensive view. In: Voss, C. (Ed.), Manufacturing Strategy: Process and Content. Chapman \& Hall, London, pp. 297-317.

Lekurwale, R.R., Akarte, M.M., Raut, D.N., 2015. Framework to evaluate manufacturing capability using analytical hierarchy process. Int. J. Adv. Manuf. Technol. 76, 565-576. https://doi.org/10.1007/s00170-014-6284-7.

Lind, S., Olsson, D., Sundin, E., 2014. Exploring inter-organizational relationships in automotive component remanufacturing. J Remanufact 4 (5). https://doi.org/ $10.1186 / 2210-4690-4-5$.
Lindahl, M., Sundin, E., Östlin, J., 2006. Environmental issues within the remanufacturing industry. Leuven, Belgium. In: Proceedings of the $13^{\text {th }}$ CIRP International Conference on Life Cycle Engineering, pp. 447-452.

Lindkvist Haziri, L., Sundin, E., Sakao, T., 2019. Feedback from remanufacturing: its unexploited potential to improve future product design. Sustainability 11 (15), 1-24. https://doi.org/10.3390/su11154037.

Lu, Q., Goh, M., Garg, M., De Souza, R., 2014. Remanufacturing in Asia: location choice and outsourcing. Int. J. Logist. Manag. 25 (1), 20-34. https://doi.org/ 10.1108/ijlm-10-2012-0125.

Lund, R.T., 1984. Remanufacturing: the Experience of the United States and Implications for Developing Countries. The World Bank, Washington, D.C.

Lundmark, P., Sundin, E., Björkman, M., 2009. Industrial challenges within the remanufacturing system. Stockholm, Sweden. In: Proceedings of the 3rd Swedish Production Symposium.

Miltenburg, J., 2005. Manufacturing strategy In: How to Formulate and Implement A Winning Plan, nd ed., vol. 2. Productivity Press, New York.

Miltenburg, J., 2008. Setting manufacturing strategy for a factory-within-a-factory Int. J. Prod. Econ. 113 (1), 307-323. https://doi.org/10.1016/j.ijpe.2007.09.001.

Min, H., Melachrinoudis, E., 1999. The relocation of a hybrid manufacturing/distribution facility from supply chain perspectives: a case study. Omega. Int. J. Manag. Sci. 27 (1), 75-85. https://doi.org/10.1016/S0305-0483(98)00036-X.

Murray, A., Skene, K., Haynes, K., 2017. The circular economy: an interdisciplinary exploration of the concept and application in a global context. J. Bus. Ethics 140 (3), 369-380. https://doi.org/10.1007/s10551-015-2693-2.

Östlin, J., 2008. On Remanufacturing Systems: Analysing and Managing Flows and Remanufacturing Processes. Department of Management and Engineering, Linköpings universitet, Linköping.

Östlin, J., Ekholm, H., 2007. Lean production principles in remanufacturing: a case study at a toner cartridge remanufacturer. Orlando, USA. In: 15th International Symposium on Electronics and the Environment (ISEE), pp. 216-221. https:// doi.org/10.1109/ISEE.2007.369397.

Östlin, J., Sundin, E., Björkman, M., 2008. Business drivers for remanufacturing. Sydney, Australia. In: 15th CIRP International Conference on Life Cycle Engineering: Conference Proceedings, pp. 581-586.

Östlin, J., Sundin, E., Björkman, M., 2008. Importance of closed-loop supply chain relationships for product remanufacturing. Int. J. Prod. Econ. 115, 336-348. https://doi.org/10.1016/j.ijpe.2008.02.020.

Östlin, J., Sundin, E., Björkman, M., 2009. Product life-cycle implications for remanufacturing strategies. J. Clean. Prod. 17 (11), 999-1009. https://doi.org/10.1016/ j.jclepro.2009.02.021.

Parker, D., Riley, K., Robinson, S., Symington, H., Tewson, J., Jansson, K., Ramkumar, S., Peck, D., 2015. Remanufacturing market study, report from the horizon 2020 project ERN - European remanufacturing network, grant agreement No 645984. Accessible from. www.remanufacturing.eu.

Pawlik, E., Ijomah, W., Corney, J., 2013. Current state and future perspective research on lean remanufacturing - focusing on the automotive industry. IFIP Adv. Inf. Commun. Technol. 397, 429-436. https://doi.org/10.1007/978-3-642-40352-1. 54.

Säfsten, K., Johansson, G., 2005. Research within the Area of Product Realisation at Swedish Universities and Research Institutes, s.L, vol. 6. VINNOVA Analys VA.

Sakao, T., Sundin, E., 2019. How to improve remanufacturing?-a systematic analysis of practices and theories. J. Manuf. Sci. Eng. 141 (2), 1-13. https://doi.org/ 10.1115/1.4041746, 021004-.

Seitz, M.A., Peattie, K., 2004. Meeting the closed-loop challenge: the case of remanufacturing. Calif. Manag. Rev. 46 (2), 74-89. https://doi.org/10.2307/ 41166211.

Skinner, W., 1969. Manufacturing - missing link in corporate strategy. Harv. Bus Rev. 47 (3), 136-145.

Subramoniam, R., Huisingh, D., Chinnam, R.B., Subramoniam, S., 2013. Remanufacturing Decision-Making Framework (RDMF): research validation using the analytical hierarchical process. J. Clean. Prod. 40, 212-220. https://doi.org/ 10.1016/j.jclepro.2011.09.004.

Sundin, E., 2004. Product and Process Design for Successful Remanufacturing. Linköping: Doctoral dissertation. Linköping University Electronic Press.

Sundin, E., 2006. How can remanufacturing processes become leaner?. Leuven, Belgium. In: Proceedings of 13th CIRP Int. Conf. On Life Cycle Engineering, May 31 - Jun. 02, pp. 429-434.

Sundin, E., Bras, B., 2005. Making functional sales environmentally and economically beneficial through product remanufacturing. J. Clear Prod. 13 (9), 913-925. https://doi.org/10.1016/j.jclepro.2004.04.006.

Sundin, E., Lee, H., 2011. In what way is remanufacturing good for the environment?. In: Proceedings of the 7th International Symposium on Environmentally Conscious Design and Inverse Manufacturing, vol. 2. EcoDesign-11, Kyoto, Japan, ISBN 978-94-007-3010-6, pp. 551-556. https://doi.org/10.1007/978-94-0073010-6_106. November 30 - December.

Sundin, E., Tyskeng, S., 2003. Inverse manufacturing at electrolux or recycling at local facilities? -A comparison from environmental and economic perspectives. Tokyo, Japan, presented at the. In: Proceedings of EcoDesign 2003.

Sundin, E., Sakao, T., Lindahl, M., Kao, C.-C., Joungerious, B., 2016. Map of remanufacturing business model landscape, report from the horizon 2020 project ERN European remanufacturing network, grant agreement No 645984. Accessible from. www.remanufacturing.eu.

Thierry, M., Salomon, M., Van Nunen, J., Van Wassenhove, L., 1995. Strategic issues in product recovery management. Calif. Manag. Rev. 37 (2), 114-136. https:// doi.org/10.2307/41165792. 
Tukker, A., Tischner, U., 2006. Product-services as a research field: past, present and future. Reflections from a decade of research. J. Clean. Prod. 14 (17), 1552-1556 https://doi.org/10.1016/j.jclepro.2006.01.022.

Vogt Duberg, J., Johansson, G., Sundin, E., Tang, O., 2020. Economic Evaluation of Potential Locations for Remanufacturing in an Extended Supply Chain - A Case Study on Robotic Lawn Mowers. Grenoble, France, 27th CIRP Life Cycle Engineering (LCE) (Accepted)

Wei, S., Tang, O., Sundin, E., 2015. Core (product) Acquisition Management for remanfuacturing: a review. J Remanufact 5 (4), 1-27. https://doi.org/10.1186/ s13243-015-0014-7.

Wheelwright, S.C., 1984. Manufacturing strategy: defining the missing link. Strat Manag. J. 5 (1), 77-91. https://doi.org/10.1002/smj.4250050106.

Yang, M., Smart, P., Kumar, M., Jolly, M., Evans, S., 2018. Product-service systems business models for circular supply chains. Prod. Plann. Contr. 29 (6), 498-508. https://doi.org/10.1080/09537287.2018.1449247. 